\title{
A nondimensional framework for exploring the relief structure of landscapes
}

\author{
Stuart W. D. Grieve ${ }^{1}$, Simon M. Mudd ${ }^{1}$, Martin D. Hurst ${ }^{2}$, and David T. Milodowski ${ }^{1}$ \\ ${ }^{1}$ School of GeoSciences, University of Edinburgh, Drummond Street, Edinburgh EH8 9XP, UK \\ ${ }^{2}$ British Geological Survey, Keyworth, Nottingham NG12 5GG, UK \\ Correspondence to: Stuart W. D. Grieve (s.grieve@ed.ac.uk)
}

Received: 9 December 2015 - Published in Earth Surf. Dynam. Discuss.: 14 January 2016

Revised: 17 March 2016 - Accepted: 30 March 2016 - Published: 8 April 2016

\begin{abstract}
Considering the relationship between erosion rate and the relief structure of a landscape within a nondimensional framework facilitates the comparison of landscapes undergoing forcing at a range of scales, and allows broad-scale patterns of landscape evolution to be observed. We present software which automates the extraction and processing of relevant topographic parameters to rapidly generate nondimensional erosion rate and relief data for any landscape where high-resolution topographic data are available. Individual hillslopes are identified using a connected-components technique which allows spatial averaging to be performed over geomorphologically meaningful spatial units, without the need for manual identification of hillslopes.

The software is evaluated on four landscapes across the continental United States, three of which have been studied previously using this technique. We show that it is possible to identify whether landscapes are in topographic steady state. In locations such as Cascade Ridge, CA, a clear signal of an erosional gradient can be observed. In the southern Appalachians, nondimensional erosion rate and relief data are interpreted as evidence for a landscape decaying following uplift during the Miocene. An analysis of the sensitivity of this method to free parameters used in the data smoothing routines is presented which allows users to make an informed choice of parameters when interrogating new topographic data using this method. A method to constrain the critical gradient of the nonlinear sediment flux law is also presented which provides an independent constraint on this parameter for three of the four study landscapes.
\end{abstract}

\section{Introduction}

The Earth's surface evolves dynamically in response to the interplay of climatic, tectonic and other factors operating at timescales ranging from minutes to millennia. Highresolution topographic data generated from terrestrial and airborne laser scanning, in combination with increased computational power, has facilitated a revolution in geomorphology, allowing the quantitative interrogation of landscape form to provide insight into the forces shaping a landscape. Relationships have been found between topography and the tectonic (e.g., Wobus et al., 2006; Hilley and Arrowsmith, 2008; DiBiase et al., 2012; Hurst et al., 2013a), climatic (e.g., Gabet et al., 2004; Anders et al., 2008; Champagnac et al., 2012), and biotic (e.g., Roering et al., 2010; Milodowski et al., 2015a) forcing of a landscape in addition to links be- tween topography and bedrock properties (e.g., Korup, 2008; Clarke and Burbank, 2010, 2011; Hurst et al., 2013b).

Such fundamental relationships provide important insight into landscape evolution; however, many of these techniques are challenging to implement, due to variable or poorly defined methods, or require proprietary software to obtain data. This highlights the need for standardized techniques and tools to allow the analysis of topographic data to be reproduced and falsified, strengthening our understanding of the processes that shape planetary surfaces. In this contribution we focus on methods exploiting high-resolution topographic data in soil-mantled landscapes that aim to elucidate both sediment flux laws (see Dietrich et al., 2003) and the transient evolution of landscapes (e.g., Hurst et al., 2013a). 
Our approach is rooted in a nondimensional framework that describes relationships between erosion rates and hillslope topography in soil-mantled landscapes (Roering et al., 2007). This framework facilitates the direct comparison of landscapes of widely varying morphology and process. It has been shown to provide compelling insight into the identification of landscape transience (Hurst et al., 2012), complex tectonic signals from topography (Hurst et al., 2013a), and process controls on the density of channels (Sweeney et al., 2015). Extracting the nondimensional parameters from highresolution topography can be difficult, subject to choices about how the metrics are calculated, and there has been no investigation into how different methods might influence results, and therefore the interpretation of landscapes.

Here we present a framework and methodology for extracting the required topographic parameters and processing the resulting data. Our software uses a clear methodology to allow researchers to generate these data for new landscapes and can replicate published relationships between nondimensional erosion rate and relief. Such relationships can be used to discriminate between landscapes in topographic steady state, where erosion rate is balanced by uplift rate, and those undergoing transience or topographic decay.

Additionally we present a method for generating spatially contiguous hilltop patches, required as a spatial averaging tool in many studies (e.g., Perron et al., 2009; Hurst et al., 2012, 2013a) to identify individual hillslopes for analysis. An analysis on the influence of spatial averaging and data smoothing on the interpretation of topographic data is undertaken and hillslope and basin average data are also used to estimate the critical gradient, a key parameter in the nonlinear sediment flux model.

\section{Theoretical background}

Numerous sediment flux laws (cf. Dietrich et al., 2003) have been developed and tested, particularly since the advent of cosmogenic radionuclide dating and high-resolution topographic measurements. In addition to the conceptually simple linear flux law (Culling, 1960; McKean et al., 1993; Tucker and Slingerland, 1997; Small et al., 1999; Booth et al., 2013), models of depth-dependent (Braun et al., 2001; Furbish and Fagherazzi, 2001; Heimsath et al., 2005; Roering, 2008) and nonlinear sediment flux (Andrews and Bucknam, 1987; Roering et al., 1999, 2001, 2007) have been employed, alongside models which directly consider sediment particle motion (Foufoula-Georgiou et al., 2010; Tucker and Bradley, 2010; Furbish and Roering, 2013).

Models which consider particle motion are challenging to apply to real topography as they do not have an analytical solution and without high-resolution soil depth information it is challenging to apply a soil-thickness-based sediment flux law to landscape-scale analysis (Grieve et al., 2016b). However, topographic predictions of the nonlinear flux law have been successfully tested (Roering et al., 2007; Grieve et al., 2016b) suggesting that it, at a minimum, can constrain broad-scale sediment transport processes across landscapes. The nonlinear flux law is (Andrews and Bucknam, 1987; Roering et al., 1999, 2001, 2007)

$\bar{q}_{\mathrm{s}}=\frac{K S}{1-\left(|S| / S_{\mathrm{c}}\right)^{2}}$,

where $S$ is the topographic gradient in dimensions of length/length (dimensions denoted in square brackets as $[L]$ ength, $[M]$ ass and [ $T$ ]ime), $S_{\mathrm{c}}$ [dimensionless] is the hillslope critical gradient, $K\left[L^{2} T^{-1}\right]$ is a sediment transport coefficient, and $\bar{q}_{\mathrm{s}}\left[L^{2} T^{-1}\right]$ is a volumetric sediment flux per unit contour length. As $S$ tends towards $S_{\mathrm{c}}$, the sediment flux asymptotically increases towards infinity, corresponding to an increase in landsliding on an increasingly planar hillslope.

Roering et al. (2007) modeled the relief structure of theoretical one-dimensional hillslopes which evolve under Eq. (1) and found that relief, the difference in elevation between a hilltop and the point on the channel it is coupled to, is controlled by the erosion rate, hillslope length, and the sediment transport coefficient. Equation (1) has been found to be consistent with observations of topography and erosion rates across several landscapes (e.g., Roering et al., 1999, 2007; Roering, 2008; Hurst et al., 2012)

Roering et al. (2007) normalized relationships describing these one-dimensional hillslopes using topographic parameters to produce a dimensionless erosion rate,

$E^{*}=\frac{E}{E_{\mathrm{R}}}=\frac{\rho_{\mathrm{r}}}{\rho_{\mathrm{s}}} \cdot \frac{2 E L_{\mathrm{H}}}{K S_{\mathrm{c}}}=\frac{-2 C_{\mathrm{HT}} L_{\mathrm{H}}}{S_{\mathrm{c}}}$,

where $E\left[L T^{-1}\right]$ is the erosion rate, $\rho_{\mathrm{r}}$ and $\rho_{\mathrm{S}}\left[M L^{-3}\right]$ are the rock and soil bulk densities, respectively, $C_{\mathrm{HT}}\left[L^{-1}\right]$ is the hilltop curvature, $L_{\mathrm{H}}[L]$ is the hillslope length, $E_{\mathrm{R}}\left[L T^{-1}\right]$ is a reference erosion rate denoted as

$E_{\mathrm{R}}=\frac{K S_{\mathrm{c}}}{2 L_{\mathrm{H}}\left(\rho_{\mathrm{r}} / \rho_{\mathrm{s}}\right)}$,

and the dimensionless relief is given as

$R^{*}=\frac{R}{S_{\mathrm{c}} L_{\mathrm{H}}}$,

where $R[L]$ is the topographic relief. Parabolic hillslope profiles are generated when $E^{*}$ values are less than or equal to 1 , such that $R^{*}$ increases approximately linearly with erosion rate. Planar hillslopes near the critical gradient, $S_{\mathrm{c}}$, indicate that $R^{*}$ is insensitive to erosion rate when $E^{*}$ approaches or exceeds 1 . This prediction is consistent with observations that, when erosion rates are high, relief becomes limited by a critical slope angle, set by the material properties of the underlying bedrock (e.g., Binnie et al., 2007; DiBiase et al., 2012). A combination of high $E^{*}$ and $R^{*}$ values indicates a landscape with steep, planar hillslopes and frequent landsliding, whereas low values suggest more convex hillslopes with lower overall relief (Roering et al., 2007). 
For landscapes in topographic steady state with uniform erosion rates, values of $E^{*}$ and $R^{*}$ will plot on the steadystate curve described by

$R^{*}=\frac{1}{E^{*}}\left(\sqrt{1+\left(E^{*}\right)^{2}}-\ln \left(\frac{1}{2}\left(1+\sqrt{1+\left(E^{*}\right)^{2}}\right)\right)-1\right)$.

Here, we define steady state using the formulation of Mudd and Furbish (2004), which considers a hillslope to be in steady state if it retains a constant topographic form with regard to its local base level, the channel at its base. Steadystate hillslopes which experience spatially uniform erosion rates will plot on a single point on the curve (Roering et al., 2007), whereas landscapes experiencing an erosion gradient will plot at many points along this curve, as demonstrated by Hurst et al. (2012). These nondimensional landscape properties have utility beyond steady-state landscapes. Hurst et al. (2013a) used this formulation to distinguish between growing and decaying parts of a landscape by identifying hysteresis in $E^{*} R^{*}$ space. Sweeney et al. (2015) has applied similar techniques to analogue landscape evolution models to demonstrate that the efficiency of hillslope sediment transport controls drainage density. These cases of differing landscape properties and histories highlight the power of using topography and $E^{*} R^{*}$ analysis to interpret landscape evolution.

The application of such a framework to real data is limited by the challenge of applying a one-dimensional model of hillslope evolution to two-dimensional topographic data. Attempts to apply such models typically identify nonconvergent portions of the landscape upon which to perform tests through either field surveying planar hillslopes (Rosenbloom and Anderson, 1994), the algorithmic identification of convergent topography (Grieve et al., 2016b), manual identification of planar topography from digital elevation models, or the exclusion of areas of high convergence from hillslope profiles through a valley extraction algorithm as is employed by Hurst et al. (2012) and in this study. All such methods are compromises between computational efficiency, reproducibility, and the accuracy with which a onedimensional hillslope profile can be extracted. Consequently, the conclusions drawn using this, or any other, application of one-dimensional to two-dimensional data must be considered within the context of their potential errors.

\section{Hilltop patches}

The extraction of signals from high-resolution topographic data can often require smoothing of raw data to filter out both topographic and artificial noise (Lashermes et al., 2007; Roering et al., 2010; Sofia et al., 2013). This smoothing can be performed either by processing the raw digital elevation model (DEM) before any analysis is performed (e.g., Roering et al., 2010) or by smoothing the output data (e.g., Tucker et al., 2001; Tarolli and Dalla Fontana, 2009). In order to understand landscape properties at a hillslope scale it is often desirable to perform local smoothing to group individual DEM pixels into collections of pixels that correspond to individual hilltops and their connected hillslopes.

This was performed by Hurst et al. (2012) through a process of vectorizing hilltops, then splitting the vectors by a threshold length and discarding all split segments shorter than an arbitrary length of $50 \mathrm{~m}$. The final split vectors are then converted back into rasters in order to create a network of hilltop patches of a defined minimum length. These patches are typically 2 pixels wide, spanning both sides of a drainage divide. This technique is challenging to reproduce, as it relies upon several user-defined parameters and a subjective assessment of which vector segments to discard.

\subsection{Automated generation of hilltop patches}

Connected-components analysis is a technique typically used in computer vision to label contiguous pixels in raster images (e.g. Rosenfeld and Pfaltz, 1966; Samet, 1981; Lumia et al., 1983; Dillencourt et al., 1992; Suzuki et al., 2003; He et al., 2013). Here, we implement a computationally efficient connected-components algorithm developed by $\mathrm{He}$ et al. (2008) to generate contiguous hilltop patches, resulting in a network of hilltop patches, each coded with a unique ID number (Fig. 2). Finally, in order to allow better replication of the original concepts used in Hurst et al. (2012), a minimum patch area can be supplied, which is used to remove any hilltop patches which are smaller than this user-defined threshold.

This hilltop patch identification method is very efficient and has been demonstrated to operate effectively on large, complex images (He et al., 2008) without an impact on performance. This technique has utility beyond $E^{*} R^{*}$ calculations, as it can be used in any work where discrete patches of hilltop need to be identified (e.g., Perron et al., 2009) or where individual hillslopes must be analyzed using topographic data.

\section{Generating topographic data}

\subsection{Extraction of a channel network}

A key component of most topographic analysis is the delineation of a channel network, without which many topographic parameters cannot be estimated. Channel networks can be extracted by using either a process-based method which uses the stream power model to identify the point in a landscape where fluvial processes begin to dominate over hillslope processes (Clubb et al., 2014) or by using a geomorphometric method which identifies channels using curvature thresholds (Passalacqua et al., 2010; Orlandini et al., 2011; Pelletier, 2013).

In order for the $E^{*} R^{*}$ data to capture the true range of erosion rates and reliefs inherent in a landscape, it is im- 


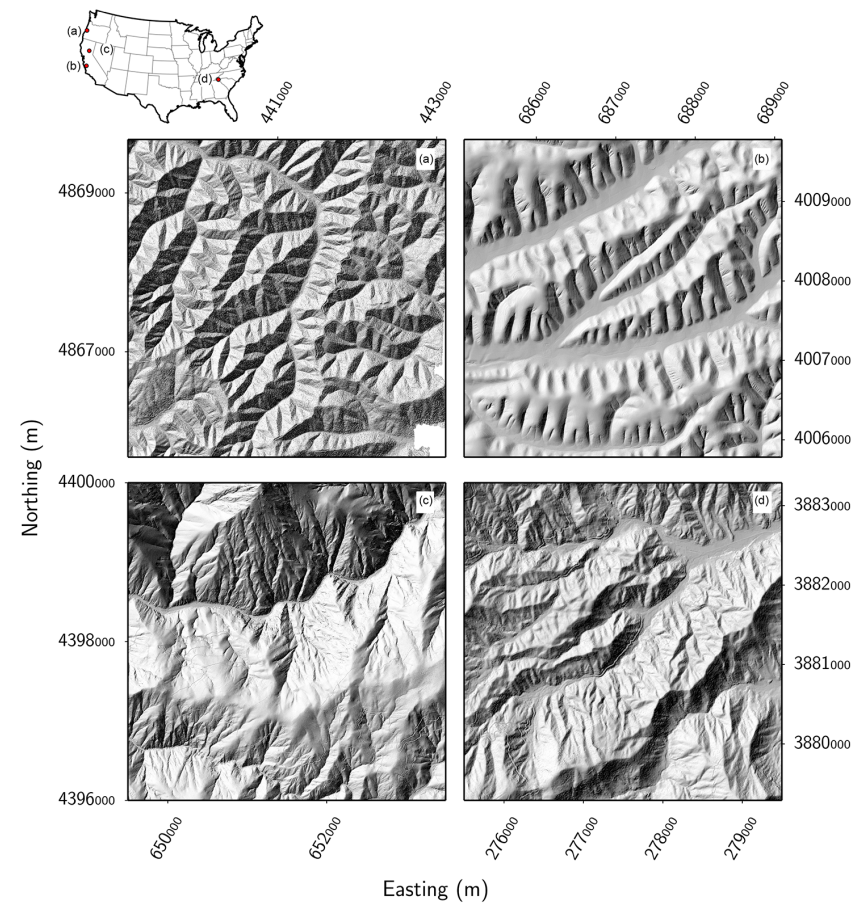

Figure 1. Map of the locations of each field site within the continental USA with a shaded relief map of characteristic sections of each location's topography. All coordinates are in UTM. (a) Oregon Coast Range, Oregon, UTM Zone 10N. (b) Gabilan Mesa, California, UTM Zone 10N. (c) Northern Sierra Nevada, California, UTM Zone 10N. (d) Coweeta, North Carolina, UTM Zone 17N.

portant to define a channel network which correctly identifies the hillslope-fluvial transition, including the delineation of colluvial channels, which are often challenging to identify using non-geomorphometric methods (Pelletier, 2013). Here we follow Pelletier (2013) and apply a Wiener filter (Wiener, 1949) to remove noise from the raw topographic data. Subsequently, channelized portions of the drainage network are identified based on a tangential curvature threshold (e.g., Pelletier, 2013). The appropriate curvature threshold is identified from the properties of its quantile-quantile plot (e.g., Lashermes et al., 2007; Passalacqua et al., 2010). These channelized patches of the landscape are combined by performing a connected-components analysis (He et al., 2008) which merges discreet patches of channel into a contiguous channel network. Following methods outlined in Grieve et al. (2016b), floodplain masks are also created and combined with this channel network, which separates the landscape into two domains: hillslopes and channels. This has the effect of terminating hillslope traces when they reach a hollow or enter the floodplain, ensuring that the trace properties only reflect the hillslope domain and the $E^{*} R^{*}$ measurements are not contaminated by sampling parts of the landscape which the nondimensional framework does not apply to.
If the channel network is incorrectly defined, some fluvial erosion could impact the correct measurement of $E^{*} R^{*}$ values. However, due to the number of individual measurements per landscape ( $>160000$ in each case) and the small number of points on a landscape where such erroneous measurements could occur, such measurements will have little impact on landscape-scale trends, particularly when spatial averaging is applied.

\subsection{Extraction of topographic parameters}

All of the key measurements required to generate $E^{*} R^{*}$ data can be extracted from high-resolution topography (Roering et al., 2007). Calculation of $E^{*}$ using Eq. (2) requires hillslope length and hilltop curvature, and calculation of $R^{*}$ using Eq. (4) requires the relief and hillslope length to be measured from high-resolution topography.

Grieve et al. (2016b) measured hillslope length by generating overland flow paths running from hilltop to channel pixels for every hilltop in a DEM, thereby generating a diverse range of measurements shown to characterize the range of hillslope properties inherent within a landscape. From these traces, each hilltop's local relief is also measured by taking the difference between the elevation at the start (hilltop) and end (channel) of each trace. Finally, the hilltop curvature for each hilltop pixel is extracted following Hurst et al. (2012), whose techniques demonstrated that hilltop curvature scales linearly with erosion rate below hilltop gradients of 0.4 . Correspondingly, we also sample the hilltop gradient $\left(S_{\mathrm{HT}}\right)$ at the start of each trace to allow data to later be filtered by this value. By using the methods outlined by Grieve et al. (2016b) we can generate a 4-tuple of information for each hilltop pixel in the landscape containing $\left(L_{\mathrm{H}}, R, C_{\mathrm{HT}}, S_{\mathrm{HT}}\right)$.

\subsection{Smoothing topographic parameters}

In previous studies that generate $E^{*} R^{*}$ data, some form of smoothing has been employed to extract meaningful trends from the inherently noisy topographic data. Roering et al. (2007) hand-selected basins with uniform morphologies and minimal anthropogenic disturbance to measure topographic parameters from, effectively removing the majority of noise in the landscape and producing a small number of data points considered to be characteristic of their two steady-state landscapes.

Hurst et al. (2012) used semi-automated methods to extract the required topographic parameters, and averaged the resulting data spatially over hilltop segments of a defined minimum length. Hurst et al. (2013a) utilized the same methodology, but further averaged the data by grouping segments into bins defined by their distance along the Dragon's Back pressure ridge so as to explore the topographic expression of a transient uplift signal along the ridge. As these techniques do not self-select idealized hillslopes or basins as in Roering et al. (2007), some filtering of the raw data was re- 
quired (see Sect. 5.1). These latter methods allow $E^{*} R^{*}$ data to be used to interrogate transient landscapes, increasing the power of the method and providing a vital tool in the topographic analysis of landscapes.

Here, we extract topographic parameters from raw topographic data and smooth the resulting measurements, in accordance with previous authors' methods, firstly performing spatial averaging at a basin scale. The basins that are used to average the topographic parameters can be defined in an automated manner to produce an average value over all basins of a given stream order, or a more user-defined approach can be undertaken to select basins manually in order to more closely replicate the work of Roering et al. (2007). Secondly the parameters can be averaged at a hillslope scale by using the discrete hilltop patches generated using the technique outlined in Sect. 3.1. The data are filtered using the same constraints outlined in Hurst et al. (2012), removing hilltops with a $S_{\mathrm{HT}}>0.4$ or a patch size $<50 \mathrm{~m}$, with the additional filtering of hillslope length and relief values below a userdefined threshold, typically 2-5 $\mathrm{m}$ for each parameter; this ensures that hilltops sampled are true hilltops and are not interfluves sitting adjacent to a basin outlet, which will not conform to models of hillslope sediment transport. The data are also returned to the user filtered, but not averaged, allowing users to explore the raw data to ensure that the smoothed data are a good reflection of the overall trends inherent in a landscape. Example basins and hilltop patches, used in the smoothing routines and the hillslope traces which produce the topographic measurements, are displayed in Fig. 2.

\section{Processing the topographic data}

Once the topographic data have been extracted, they are filtered to ensure that only data which conform to the nondimensional framework described by Roering et al. (2007) are used in any further analysis.

\subsection{Filtering}

The key filtering process which must be performed is the removal of any data points which have an $S_{\mathrm{HT}}$ above 0.4. This is the threshold gradient beyond which sediment flux no longer scales linearly with slope and thus hilltop curvature does not reflect erosion rate, for $K$ values representative of published values for our field sites (Roering et al., 1999, 2007; Matmon et al., 2003; Hurst et al., 2012). Therefore data points with gradients above this value cannot be used in Eq. (2) as a proxy for erosion rate. Across all of the data sets, gradients which exceed 0.4 are removed from further analysis. In the case of the two spatially averaged data sets, individual hilltop pixels which exceed this threshold gradient within a patch or basin are removed from the averaging process for each measurement, ensuring that no invalid data contribute to the final calculations. To ensure the validity of each basin average measurement, a count of the valid pix-

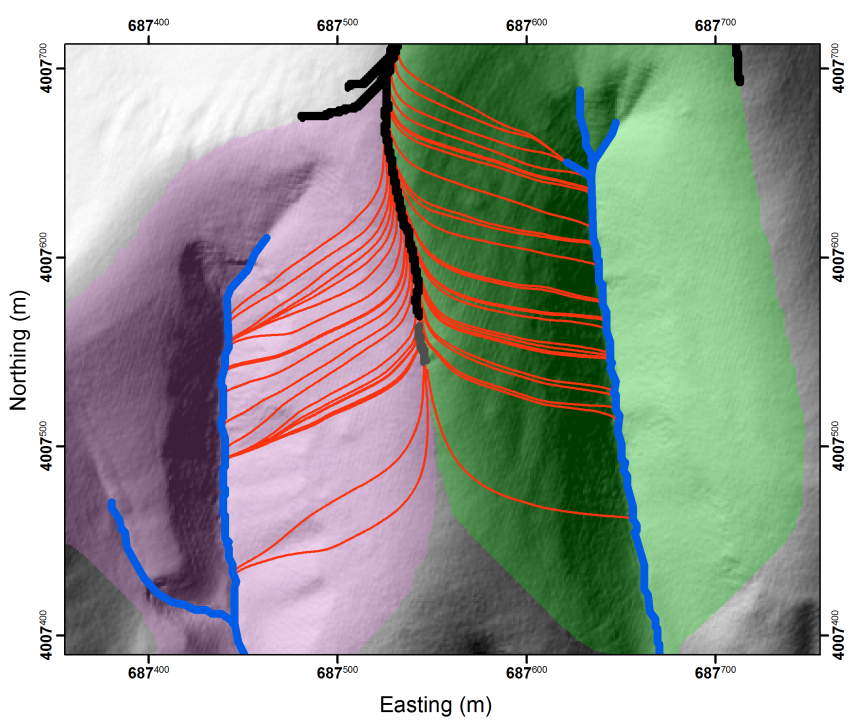

Figure 2. Map of a section of Gabilan Mesa, California (UTM Zone $10 \mathrm{~N}$ ), showing the examples of the spatial units used in the analysis of $E^{*} R^{*}$ data. Two second-order basins, colored green and purple, are bisected by a ridge with two hilltop patches, a large black patch and a smaller grey patch. From these patches, representative hillslope traces, outlined in red, travel down the hillslope and terminate at the channel network. Only $10 \%$ of the total traces generated for this ridge have been plotted and other surrounding hilltop patches and their associated traces are not displayed, to aid clarity. Coordinates are in meters.

els contained within each basin following gradient filtering is performed and any basins with fewer valid measurements than a user-defined threshold can be removed from the analysis. This threshold is typically equal to the minimum patch size used in Sect. 3.1 as this provides consistency between measurements.

\subsection{Log binning}

One method of non-spatial averaging of geomorphic data used effectively to generate slope-area plots (e.g., Tarolli and Dalla Fontana, 2009) is log binning. Such a method provides an opportunity to interrogate the data at a landscape scale while still removing the noise inherent in topographic measurements. Each $E^{*} R^{*}$ pair is placed into evenly spaced bins in base 10 logarithmic space. The bin spacing is a function of the number of bins specified by the user, and the range of $E^{*}$ values within the data set and its impact on interpretation of the data is considered in Sect. 6.2.3. To ensure that a valid number of data points make up each bin, a minimum bin size can also be specified by the user; this value will depend on the size and nature of the data set.

This type of averaging will work best in landscapes where an erosion gradient is expected, as it will produce a range of $E^{*} R^{*}$ values across the domain, as can be seen in Hurst et al. (2012). In presumed steady-state locations such as Gabilan 
Mesa most of the data are expected to cluster around a single point (Roering et al., 2007), and so imposing evenly spaced bins in log space onto such data may construct an artificial trend. It is therefore recommended to consider the raw data in conjunction with the binned data to ensure that the trends in the data are valid.

\subsection{Visualizing data}

The software allows the user to plot any combination of the $E^{*} R^{*}$ data sets, facilitating the rapid generation of basin and landscape average data following Roering et al. (2007), hilltop-averaged and log-binned data following Hurst et al. (2012, 2013a), and raw data which have previously not been available. It is also possible to interrogate the raw measurements as a density plot, which more accurately conveys the trends in the raw data as in large landscapes many measurements share the same location in $E^{*} R^{*}$ space. By allowing simple inter-comparisons between plotting methods it becomes trivial to assess the most suitable data visualization techniques for a specific landscape.

\section{Results and discussion}

By using data from previous studies which utilize $E^{*} R^{*}$ analysis, it is possible to assess the ability of this software to reproduce existing results in addition to understanding how the varying techniques for smoothing the data, discussed in Sect. 4.3, can impact on the interpretation of the processes operating on a landscape. Four landscapes in the continental USA have been selected to evaluate the software: the Oregon Coast Range and Gabilan Mesa, used by Roering et al. (2007); Cascade Ridge, used by Hurst et al. (2012); and the Coweeta Hydrologic Laboratory (Fig. 1). High-resolution lidar data are available from the National Center for Airborne Laser Mapping (NCALM) for each site and each site's point cloud data have been gridded to $1 \mathrm{~m}$ resolution DEMs following Kim et al. (2006) and accuracy information for each point cloud can be found in Appendix A.

\subsection{Reproducing previous work}

\subsubsection{Oregon Coast Range and Gabilan Mesa}

The Oregon Coast Range in Oregon, USA, is a steeply incised upland landscape with dense forest cover and a humid climate (Roering et al., 1999), leading to frequent debris flows, which initiate in colluvial hollows (Stock and Dietrich, 2003). The forests of the Oregon Coast Range are dominated by hardwoods, such as Oregon maple (Acer macrophyllum), and coniferous forest such as Douglas fir (Pseudotsuga menziesii) (Schmidt et al., 2001). Extensive work has been carried out to estimate the uplift rate of the range using marine terrace data (Kelsey et al., 1996), and these estimates of uplift rate correspond to erosion rates measured using cosmogenic radionuclides (e.g., Heimsath et al., 2001). This correspondence between uplift and erosion rate has been used to infer that the Oregon Coast Range is in steady state (e.g., Reneau and Dietrich, 1991; Roering et al., 2007).

Gabilan Mesa in California, USA, is part of the central Coast Ranges and has a semiarid Mediterranean climate with higher vegetation densities on northern slopes due to microclimatic variations (Dohrenwend, 1978). The vegetation of Gabilan Mesa is characterized by a combinations of oak savannah containing blue oak (Quercus douglasii) and chaparral shrubland containing chamise (Adenostoma fasciculatum) (Shreve, 1927). The landscape is very smooth with a regular spacing of tributaries and valleys (Dohrenwend, 1978, 1979) and gentle transitions between hillslopes and channels, suggesting that diffusive processes dominate the transport of sediment on hillslopes (Roering et al., 2007). Hilltop curvature shows little variance across the landscape, and in conjunction with the regularity of valley spacing, this suggests that the landscape is in approximate topographic steady state (Roering et al., 2007; Perron et al., 2009).

Roering et al. (2007) estimated the topographic parameters $L_{\mathrm{H}}, R$, and $C_{\mathrm{HT}}$ for the Oregon Coast Range and Gabilan Mesa field sites. The characteristic hillslope length for each landscape was estimated by identifying the inflection point in a spline curve fitted though a plot of local slope against drainage area. This inflection point is considered to correspond to the transition between the hillslope and channel domain in a landscape (Montgomery and Foufoula-Georgiou, 1993; Hancock and Evans, 2006; Tarolli and Dalla Fontana, 2009; Tarolli, 2014; Tseng et al., 2015).

Roering et al. (2007) estimated mean relief by calculating the mean of the differences between the maximum and minimum elevation within a kernel of radius equal to the characteristic hillslope length for each point on the landscape. Hilltop curvature was sampled from manually defined hilltops with a gradient below $0.05 S_{\mathrm{c}}$ and averaged across each landscape. The critical gradient was calculated for the Oregon Coast Range to be 1.2 by Roering et al. (1999), and Roering et al. (2007) assumed that this value is also correct for Gabilan Mesa.

The data from Gabilan Mesa (Fig. 3a) reveal many hilltop patches which correspond closely to the predicted $E^{*} R^{*}$ values from Roering et al. (2007). The data are predominantly clustered around a single point, showing strong agreement with observations that the landscape is in approximate steady state. However, the majority of the basin average data points and a considerable number of the hilltop patch data plot below the steady-state curve, which could be interpreted as evidence for topographic decay. However, the uniform hilltop curvatures and valley spacing, coupled with measurements of long-term erosion rates, suggest that this landscape is not undergoing topographic decay (Roering et al., 2007; Perron et al., 2009). An alternative explanation for the data falling below the steady-state curve is that an $S_{\mathrm{c}}$ value of 1.2 is too large for this landscape. Grieve et al. (2016b) used similar 

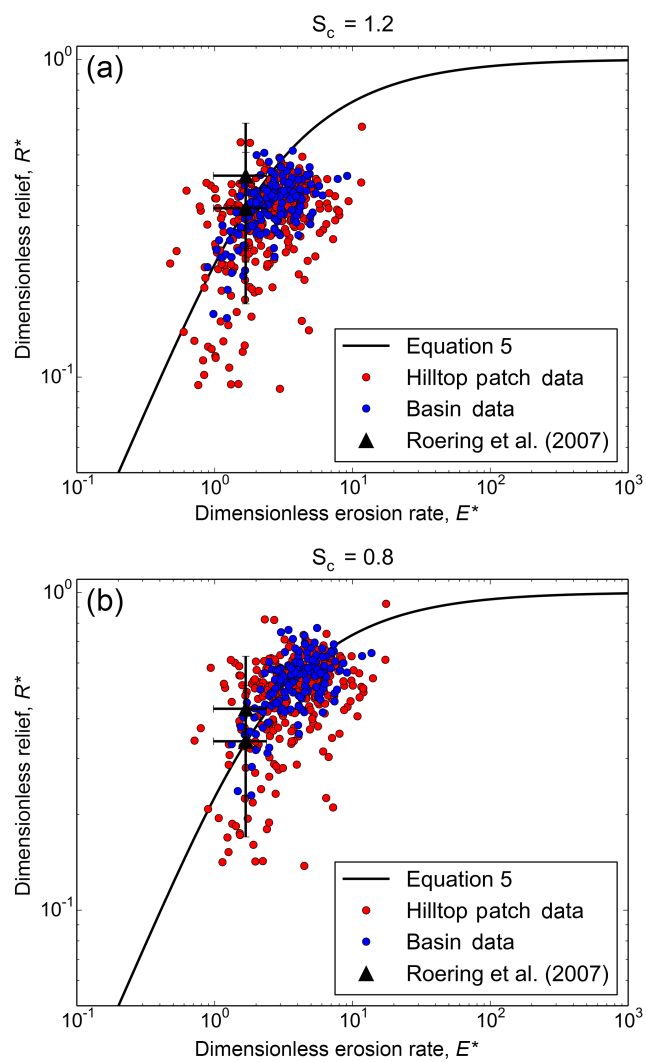

Figure 3. Hilltop patch and basin average data for Gabilan Mesa plotted using a critical gradient of 1.2 (a) and 0.8 (b) alongside data from Roering et al. (2007) for the same location. Error bars are the standard error.

topographic parameters to estimate the critical gradient for this landscape as 0.8. By replotting these data using this revised $S_{\mathrm{c}}$, the data plot more closely to the steady-state curve (Fig. 3b).

The Oregon Coast Range data are more tightly constrained than the Gabilan Mesa data (Fig. 4a), and have a similar range of $R^{*}$ values. However, as is the case for Gabilan Mesa, the majority of the data plot below the steady-state curve. This can be interpreted as evidence for topographic decay; however, due to the preponderance of evidence supporting a steady-state hypothesis for this landscape (e.g., Reneau and Dietrich, 1991; Roering et al., 2007), it is also possible that a critical gradient of 1.2 is too large in this location. By using the $S_{\mathrm{c}}$ value of 0.79 constrained by Grieve et al. (2016b), the data move closer to the steady-state curve (Fig. 4b). Using this average $S_{\mathrm{c}}$ value several $R^{*}$ measurements exceed 1. This indicates that these hillslopes are too steep to sustain soil mantle in this landscape, which corresponds to field observations of the Oregon Coast Range, where frequent shallow landsliding is reported (e.g., Benda and Dunne, 1997; Montgomery et al., 1998) and where periodic wildfires expose large (tens of square meters) patches of bedrock (Jackson and Roering, 2009).
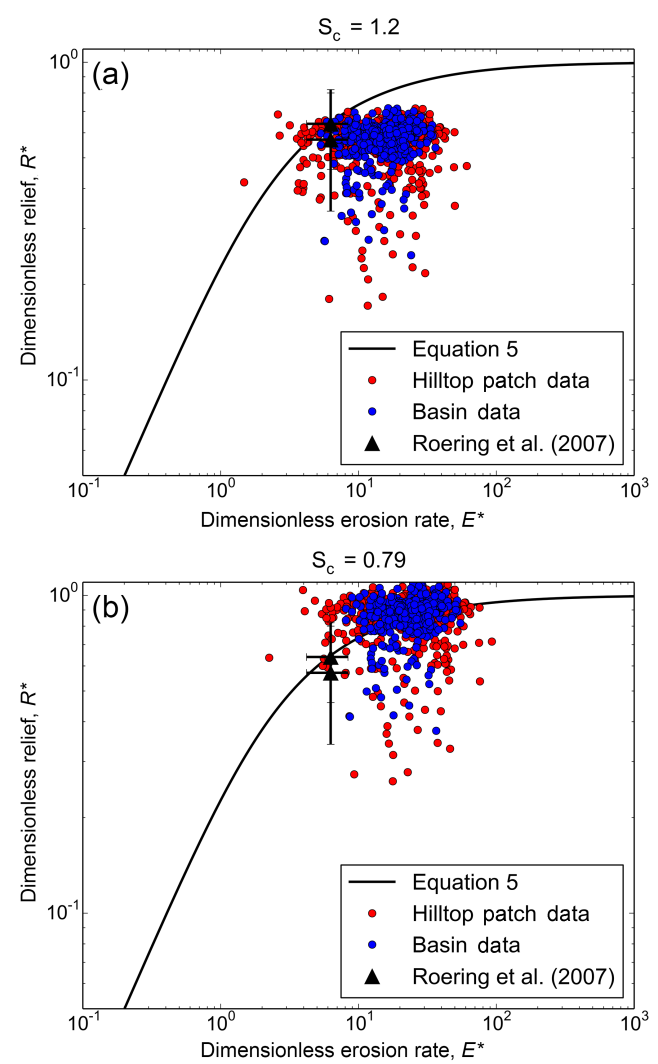

Figure 4. Hilltop patch and basin average data for the Oregon Coast Range plotted using a critical gradient of 1.2 (a) and 0.8 (b) alongside data from Roering et al. (2007) for the same location. Error bars are the standard error.

As acknowledged by Roering et al. (2007), extracting the relief from a moving window fails to capture the complete range of relief values in a landscape, resulting in an average value which dampens the true signal, reducing $R$ in high relief landscapes such as the Oregon Coast Range. Our method of measuring relief of individual hillslope traces circumvents this problem.

The majority of the data points in Figs. 3 and 4 have larger $E^{*}$ values than those from Roering et al. (2007). Grieve et al. (2016b) showed that estimating $L_{\mathrm{H}}$ using slope-area plots systematically underestimates $L_{\mathrm{H}}$ by as much as an order of magnitude in some landscapes. Such an underestimate would reduce the $E^{*}$ value for a landscape and explains the systematic differences between this study and the results of Roering et al. (2007). The larger range of hilltop patch data highlights the range of $E^{*} R^{*}$ values inherent in even a uniform landscape which is in approximate topographic steady state.

\subsubsection{Cascade Ridge}

Cascade Ridge is a section of the northern Sierra Nevada in California, USA. The landscape is predominantly forested and the climate is semiarid (Hurst et al., 2012). The charac- 
teristic topographic form of this landscape is a smooth, lowrelief relict surface which is heavily incised, creating steep canyons with an irregular spacing. The plateau surface is vegetated with oak forest including California black oak (Quercus kelloggii) and canyon live oak (Quercus chrysolepis) and pine forest containing ponderosa pine (Pinus ponderosa), Douglas fir (Pseudotsuga menziesii), and sugar pine (Pinus lambertiana), whereas the canyon is dominated by chaparal vegetation such as manzanita (Arctostaphylos spp.) (Gabet et al., 2015; Milodowski et al., 2015a). These contrasting landscape morphologies have been shown to be eroding at different rates, with the plateau surfaces eroding an order of magnitude more slowly than the canyons (Riebe et al., 2000; Hurst et al., 2012). This produces a complex landscape exhibiting a range of erosion rates influenced by climate and tectonic signals, which is not in topographic steady state (Riebe et al., 2000; Stock et al., 2004; Hurst et al., 2012; Gabet et al., 2015).

Cascade ridge is a more morphologically complex landscape than the Oregon Coast Range or Gabilan Mesa; correspondingly, the $E^{*} R^{*}$ data for this landscape are predicted to plot along the steady-state curve at a broad range of $E^{*}$ values, as was demonstrated by Hurst et al. (2012). Using an $S_{\mathrm{c}}$ value of 0.8 , as proposed by Hurst et al. (2012), produces data spanning a much wider portion of $E^{*} R^{*}$ space than the data for the steady-state landscapes of Gabilan Mesa and the Oregon Coast Range (Fig. 5a). The binned hilltop patch data show good agreement with the data from Hurst et al. (2012), spanning a similar range of $E^{*}$ values with the steady-state curve falling within the standard error of each bin. This supports observations of a range of erosion rates and landscape morphologies and highlights the utility of this method in gaining a first-order approximation of the tectonic and erosional setting of a landscape where no field data are available.

At the Cascade Ridge site, Grieve et al. (2016b) estimated $S_{\mathrm{c}}$ to be 0.72 , calculated from topographic parameters. Using this value there is little change in the trends in the data (Fig. 5b), most of the points now fall above the line and at high values of $E^{*}$, and more data points have $R^{*}$ values in excess of 1 . These high $R^{*}$ values are consistent with field observations of this transient landscape wherein rapid valley downcutting may decouple hillslopes from the channel network (Milodowski et al., 2015b) and drive shallow landsliding. In a complex landscape such as Cascade Ridge, which is known to have a broad range of erosion rates and hillslope morphologies, a landscape average $S_{\mathrm{c}}$ value will regress towards the mean. Consequently, as more of the landscape is covered by the low-gradient plateau than the steeper canyons, the $S_{\mathrm{c}}$ value of 0.72 does not reflect the parts of the landscape with larger $E^{*} R^{*}$ values, which may fall closer to the value of 0.8 used by Hurst et al. (2012).
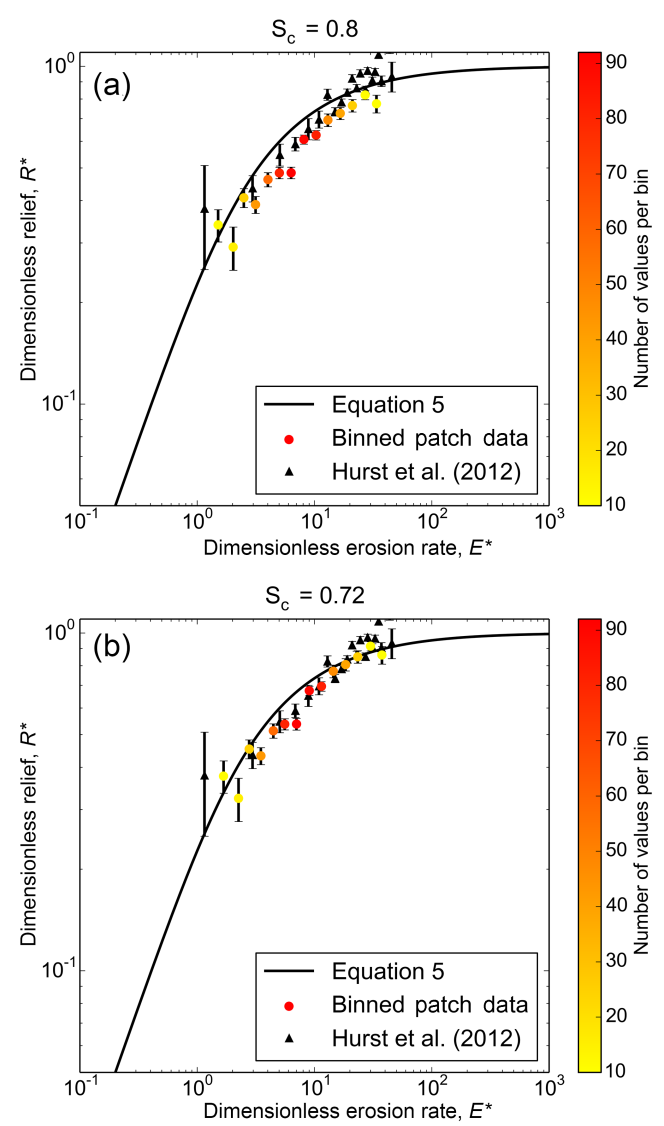

Figure 5. Binned hilltop patch data spanning a wide range of $E^{*}$ values generated using a critical gradient of 0.8 (a) and 0.72 (b) alongside data from Hurst et al. (2012) for the same location. Error bars are the standard error of the data. Error bars from Hurst et al. (2012) are generated from the original data.

\subsubsection{Coweeta}

The Coweeta Hydrologic Laboratory is in the southern Appalachian Mountains in North Carolina, USA, and is a densely vegetated landscape which exhibits classic ridge and hollow topography (Hales et al., 2012). Such topography produces many source areas for shallow landslides in colluvial hollows, which are triggered by high-intensity storms connected to hurricanes (Swift Jr. et al., 1988). The vegetation at Coweeta is a mix of shrubs, such as Rhododendron maxima, and northern hardwood forest, the distribution of which is controlled by wildfires, which in many cases are managed through human intervention (Hales et al., 2009). It is debated whether the southern Appalachians are in topographic steady state, as there is little tectonic activity, yet there is a large amount of relief preserved across the range (Baldwin et al., 2003; Matmon et al., 2003; Gallen et al., 2011, 2013).

The southern Appalachian Mountains have never previously been investigated using $E^{*} R^{*}$ methods and so can be used to evaluate the technique's ability to interrogate a complex landscape and assist in the interpretation of topographic 

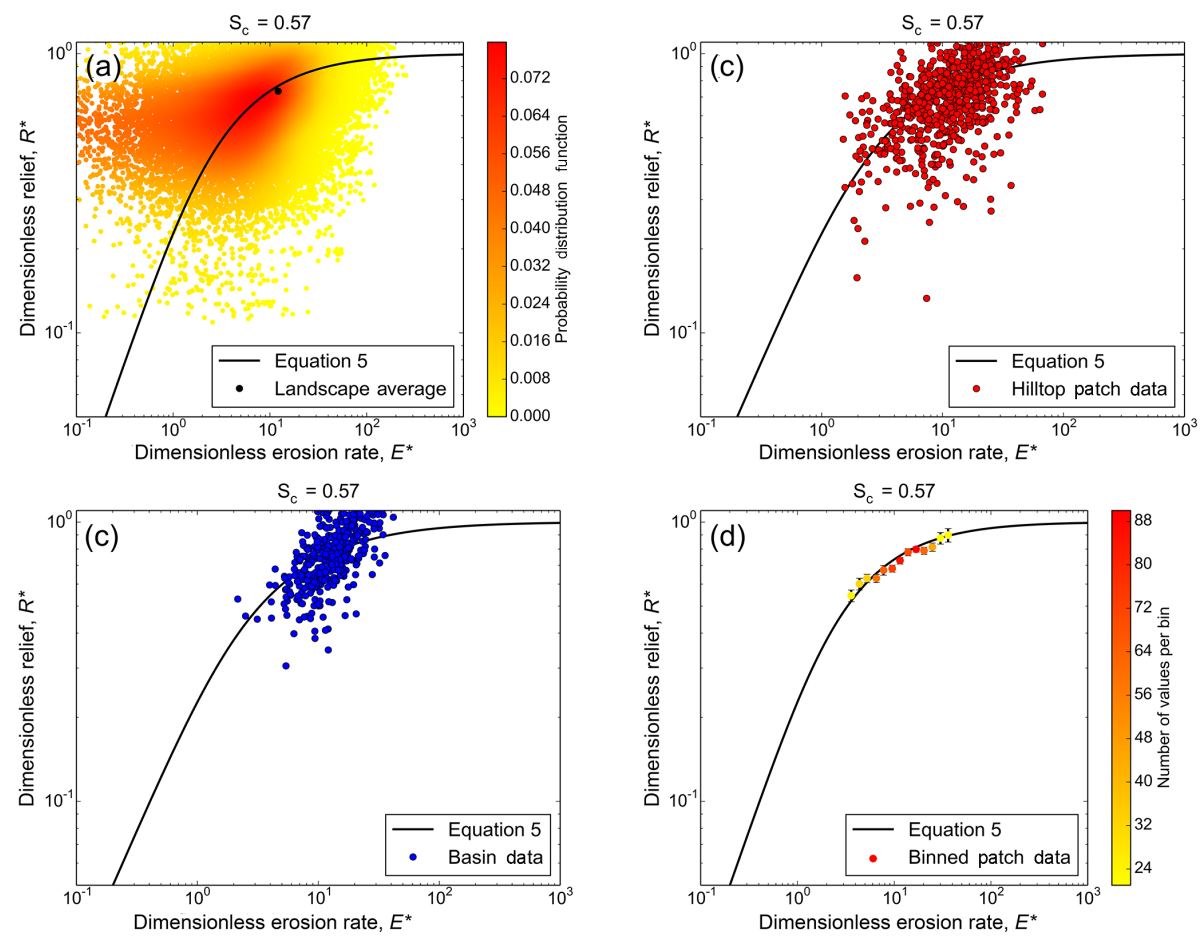

Figure 6. Comparison of the different methods which can be used to visualize $E^{*} R^{*}$ from Coweeta, using a critical gradient of 0.57. (a) Raw data colored by the density of points in $E^{*} R^{*}$ space alongside the landscape average value. Error bars plot inside the data point. (b) Data averaged over hilltop patches. (c) Data averaged over second-order drainage basins. (d) Hilltop patch data placed into logarithmically spaced bins. Error bars are the standard error.

signals. Figure 6 outlines the range of methods which can be used to interpret $E^{*} R^{*}$ data. As in Sects. 6.1.1 and 6.1.2 the critical gradient used is taken from Grieve et al. (2016b). The raw data in Fig. 6a show the range of reliefs observed in the southern Appalachians. The landscape median $E^{*} R^{*}$ value falls within the zone of maximum probability density; this highlights the level of noise inherent in high-resolution topographic data when interrogating them in $E^{*} R^{*}$ space, outlining the requirement to smooth or bin the data in order to extract meaningful information from them.

Comparing the data in Fig. $6 \mathrm{~b}$ and $6 \mathrm{c}$ to data for steadystate landscapes such as Gabilan Mesa or the Oregon Coast Range, they show similar levels of clustering, with the location of the cluster of patch and basin average values corresponding with the Oregon Coast Range data (Fig. 4). This corresponds well to field observations of hillslope morphology in these two locations, with planar hillslopes and frequent shallow landsliding reported (Benda and Dunne, 1997; Montgomery et al., 1998; Roering et al., 1999), and this clustering suggests that there is less spatial variation in erosion rate in Coweeta than in Cascade Ridge, an assertion supported by measured erosion rates from both locations (e.g., Riebe et al., 2000; Matmon et al., 2003; Hales et al., 2012; Hurst et al., 2012). Figure 6d shows the binned data for Coweeta and highlights the smaller range of $E^{*}$ values for this landscape when compared to Cascade Ridge. It also draws attention to the need to analyze $E^{*} R^{*}$ data using numerous methods to avoid an incorrect interpretation, as discussed in Sect. 5.2.

The Coweeta $E^{*} R^{*}$ data cluster around a point on the steady-state curve, and it could be concluded that this landscape is in approximate steady state. However, the value of $S_{\mathrm{c}}$ used in Fig. 6 is significantly smaller than any previously published $S_{\mathrm{c}}$ value. Field observations of Coweeta reveal that many channels are alluviated and such deposition at the base of hillslopes will alter the mean properties of a hillslope and move its idealized profile away from the model hillslopes defined by Roering et al. (2007). As a valley fills with sediment, the hillslope relief will be reduced more rapidly than other hillslope properties, due to the difference between rates of hillslope and channel response to forcing (Hurst et al., 2012). Such a reduction in relief will reduce $R^{*}$, resulting in a reduced best-fit $S_{\mathrm{c}}$ value. Such an alteration of mean hillslope properties could explain the considerable underestimation of the critical gradient when it is constrained through hillslope length-relief relationships.

The Oregon Coast Range, a broadly similar landscape to Coweeta, based on the range of $E^{*}$ values, general landscape morphology and observations of sediment transport processes, has a critical gradient of 0.79 (Grieve et al., 2016b). This value is similar to the $S_{\mathrm{c}}$ of many other landscapes (DiBiase et al., 2010; Hurst et al., 2012; Grieve et al., 2016b) and 


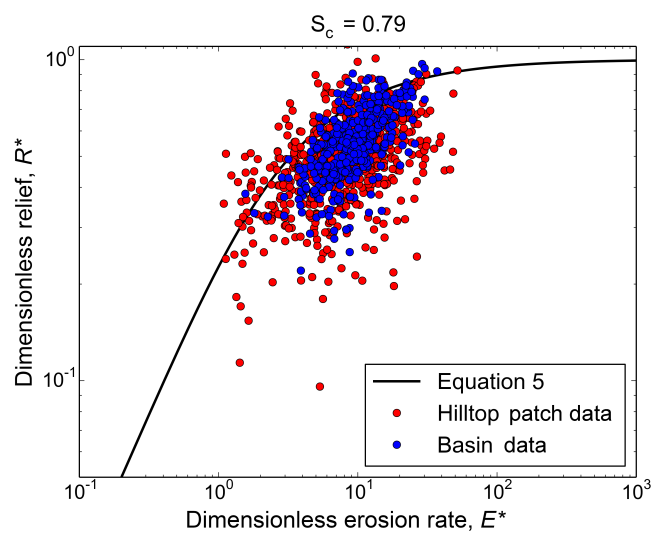

Figure 7. Hilltop patch data from Coweeta plotted using the higher $S_{\mathrm{c}}$ value of 0.79 , demonstrating that the majority of the hillslopes in this landscape plot below the steady-state curve when using a larger critical gradient.

as such we use this value to explore the patterns of $E^{*} R^{*}$ in Coweeta when a larger critical gradient which more closely resembles predicted values for other landscapes is employed. In such a case the majority of the data plot below the steadystate curve (Fig. 7). Hurst et al. (2013a) observed $E^{*} R^{*}$ data plotting below the steady-state curve, along the Dragon's Back pressure ridge, where these sections of the landscape are understood to be topographically decaying following a pulse of uplift. If this $S_{\mathrm{c}}$ is correct it could lend support to the idea of a Miocene rejuvenation of topography in the southern Appalachians (Gallen et al., 2013) followed by a period of gradual topographic decay into the present. However, the nature of sediment transport in Coweeta may not be best constrained using Eq. (1), as modeling work performed by Mudd (2016) suggests that a deviation of this magnitude from the steady-state curve indicates that a landscape is not undergoing pure nonlinear sediment flux.

\subsection{Sensitivity analysis of averaging methods}

Several of the techniques utilized to average the raw $E^{*} R^{*}$ data have free parameters, the selection of which can influence the final results. In the following section we explore the influence that averaging technique, minimum patch and basin area, basin stream order, and binning parameters can have on the interpretation of $E^{*} R^{*}$ data.

\subsubsection{Averaging methods}

As outlined in Sect. 4.3, the topographic parameters, $L_{\mathrm{H}}, R, C_{\mathrm{HT}}$, and $S_{\mathrm{HT}}$, must be smoothed in order to extract meaningful trends from the inherently noisy signal. The main technique for performing this smoothing is to spatially average the data over either hilltop patches or drainage basins. These averages can be computed as either the mean or the median of each spatial area. Figure 8 presents a comparison
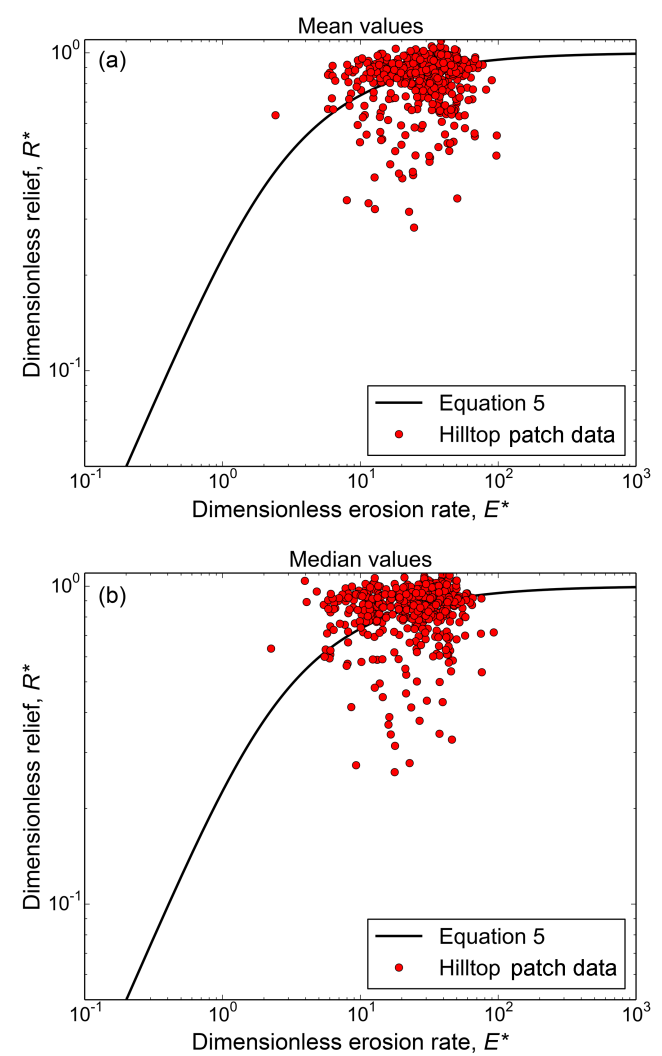

Figure 8. Comparison between hilltop patch values generated using a spatial mean (a) and a spatial median (b) for the Oregon Coast Range.

between hilltop patch data computed using means and medians for the Oregon Coast Range, showing little change between the measurements using the two techniques. Because there is little difference between the two methods, we use median values throughout this paper, as this ensures that any extreme values will have a lesser impact on landscape-scale metrics.

\subsubsection{Spatial averaging parameters}

The hilltop patch identification process described in Sect. 3.1 requires one user-defined parameter, the minimum patch area. This value is used to remove any small patches from the analysis and is included to ensure that patches conform to geomorphologically significant hillslopes, and not small patches of hilltop that are not representative of the hillslope as a whole. By varying the size of the minimum patch area from 0 through to 500 pixels it is possible to observe how this parameter can impact the interpretation of $E^{*} R^{*}$ data (Fig. 9a). As the threshold is increased, fewer patches are considered valid and the density of the data is reduced, having the effect of removing many of the outlying data points. This reinforces the need to set a minimum size for a hilltop 


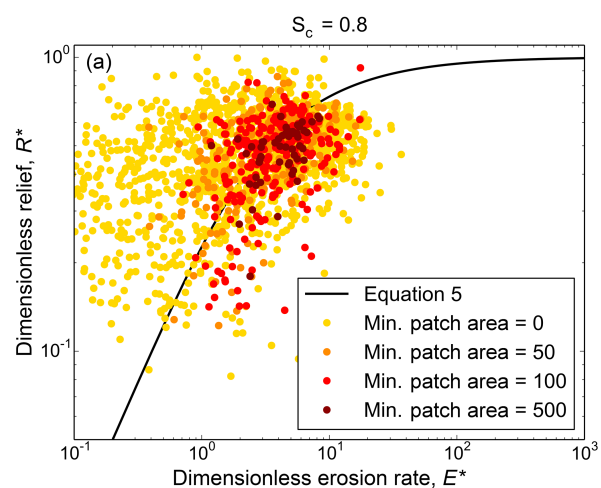

$\mathrm{S}_{\mathrm{c}}=0.8$

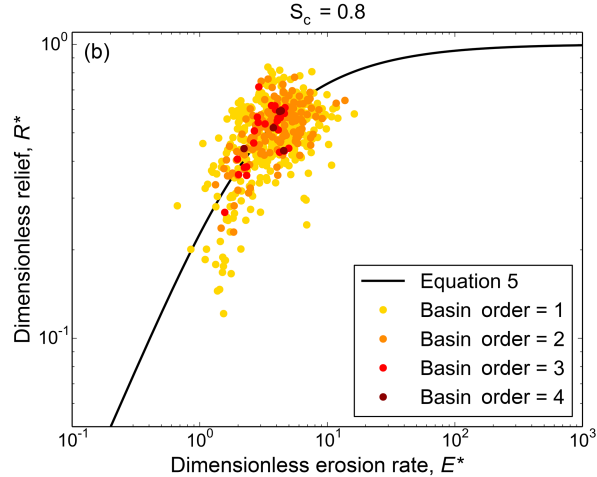

$S_{c}=0.8$

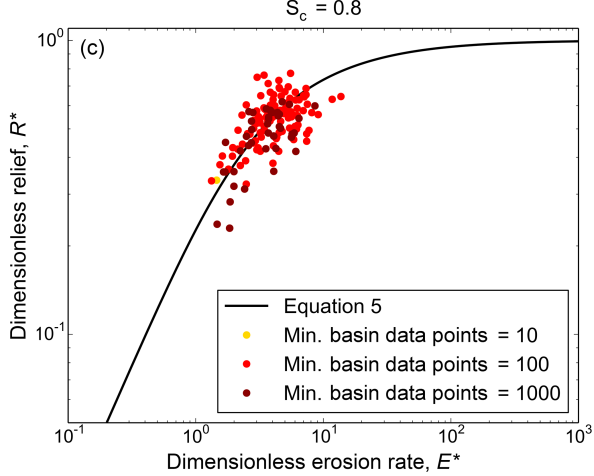

Figure 9. Comparison of the influence of changing spatial averaging method on the interpretation of $E^{*} R^{*}$ data for Gabilan Mesa. (a) Variations in the minimum patch area threshold from 0 (no threshold) to 500 pixels highlighting the reduction in noise when a minimum patch area is applied. (b) Increasing the basin steam order, which reduces variance in the data, as bigger basins are sets containing basins of smaller orders, dampening any extreme values. (c) Variations in the minimum basin pixels threshold. Outlying basins have very few data points, so they are influenced more strongly by single atypical values.

patch to ensure that a small number of measurements do not have too large an impact on the interpretation of the data.

The technique in Sect. 3.1 has no method to limit the maximum size of the hilltop patches, as the aim is to find spatially contiguous zones of hilltop and artificially breaking these patches may result in oversampling some sections of a landscape. Large patches make up a very small proportion of the total population of patches and correspondingly do not have a large impact on the overall trends in an individual data set.

The stream order of the basin used to generate basin average values will also have an influence on the interpretation of the results. Grieve et al. (2016b) used second-order basins to generate basin average topographic parameters as this order generated a large number of basins which all had a large enough area to generate numerous data points per basin, effectively sampling as much of the landscape as possible. Figure $9 b$ shows the effect of increasing the stream order of the basins used in Coweeta from first to fourth order. As each increasing order basin can be considered a set containing the previous order basins, the basin average points all plot in very similar locations in $E^{*} R^{*}$ space, suggesting that increasing basin order may be a useful method of smoothing basin average data in noisy landscapes. However, this comes with the limitation that, as the basin order increases, the number of basins in a landscape decreases, resulting in fewer data points representing larger spatial areas and the possible homogenization of topographic signals occurring at spatial scales smaller than the average basin area.

The number of valid data points contained within a basin used to generate an average value is another free parameter that the user must set. As with the hilltop patch area, selecting a sensible value is important to ensure that each basin average data point corresponds to the basin as a whole and not just a spatial subset. As the threshold is increased, outlying basins are removed (Fig. 9c), indicating that many outlying data points are generated by a small number of irregular hillslopes in otherwise typical basins. However, if the threshold is too large, too many basins will be excluded. In order to ensure consistency between spatial averaging techniques it is recommended that the minimum number of pixels in a basin be kept equal with the minimum patch area.

\subsubsection{Log bin parameters}

When computing logarithmically spaced bins there are two free parameters, the number of bins (equivalent to the bin width) and the minimum number of data points which must fall within a bin for the binned point to be valid. Figure 10a highlights the influence of changing the number of bins on the interpretation of the Cascade Ridge data. If the number of bins are too low, it becomes difficult to identify a trend in the data as the nature of a landscape can vary considerably across large ranges of $E^{*}$, and by homogenizing these measurements a transient signal can be lost.

However, as the number of bins is increased, fewer values are placed into each bin, meaning that if there is a single value which is significantly different to the rest of the values in the bin, it can vastly alter the result. It is also the case that, as the number of bins increases, the chance of a bin being removed for having too few data points increases, which will be particularly apparent at low and high $E^{*}$ values, where the 

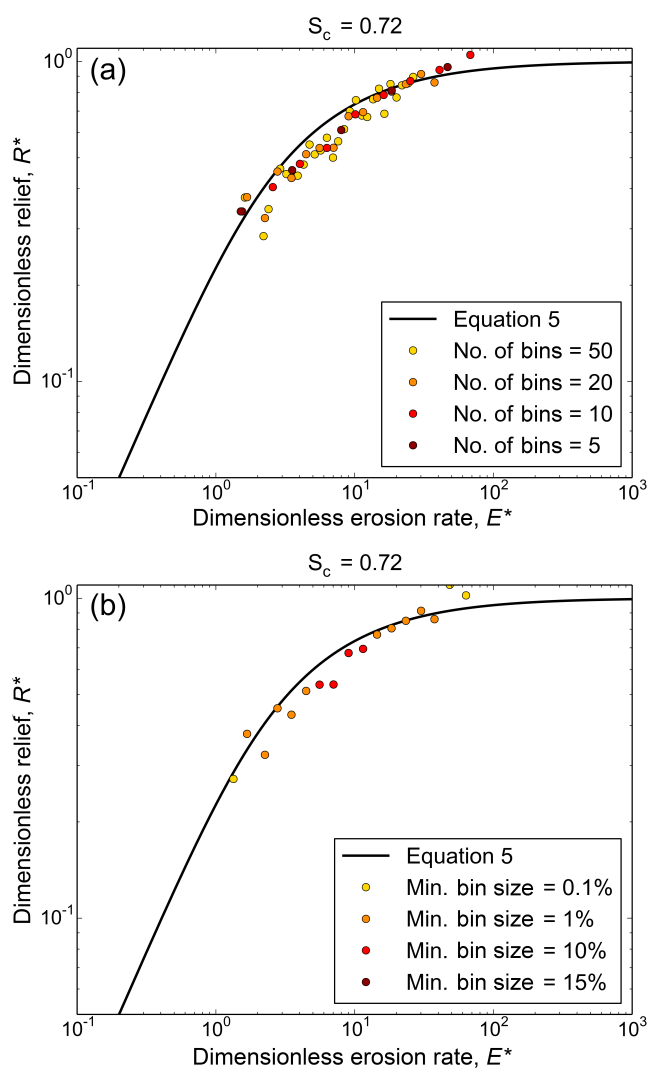

Figure 10. Comparison of the influence of binning parameters on the interpretation of $E^{*} R^{*}$ data for Cascade Ridge. (a) Varying the number of bins used, equivalent to the bin width in $E^{*}$ space. As the number of bins reduces it becomes harder to identify patterns in the data, and as the number of bins increases, the number of data points in each bin reduces, thereby reducing the power of the binning technique. (b) Varying the minimum number of data points required in a basin. As this value increases, fewer points are preserved, which compresses the range of the data and can obscure the observation of an erosional gradient. Too small a threshold can result in bins containing very few values which do not represent the landscape as a whole.

data are sparser. We have found that using 20 bins reaches a good compromise between data density and data smoothing, and corresponds well with the 21 bins used by Hurst et al. (2012), where no filtering was performed based on bin size.

The minimum size of each bin can also have an impact on the final interpretation of the data. If no threshold is applied, some bins can contain a single value, while others can contain hundreds of values, which makes interpreting the data difficult as one cannot be sure of the robustness of each binned value. If the threshold is placed too high, then valid data will not be included in the final analysis and the interpretation of a landscape's evolution could be incorrect. Figure 10b highlights this issue using data from Cascade Ridge at a range of bin size thresholds, identified as percentages of the total data set size. We have found that using a minimum bin size of $1-5 \%$ of the total data set ensures a good binning result.

\subsection{Constraining $S_{\mathrm{C}}$}

Landscapes which are in topographic steady state should plot at a single location on the curve described by Eq. (5). In principle this would mean that an erosion gradient would be required in order to constrain $S_{\mathrm{c}}$, by fitting the data to the steady-state curve. However, as observed in Figs. 3 and 4, even in idealized steady-state landscapes, there is still considerable variability in the $E^{*} R^{*}$ data. This variability is consistent with patterns of dynamic reorganization of loworder drainage basins within models of steady-state landscapes performed by Reinhardt and Ellis (2015). Therefore, it becomes possible to estimate the critical gradient of the nonlinear sediment flux law (Eq. 1) for a landscape without a strong erosion gradient, using $E^{*} R^{*}$ data.

As with previous analyses, the raw data must be spatially averaged in order to reduce the level of noise present in $E^{*} R^{*}$ space before an estimate of $S_{\mathrm{c}}$ can be made. The optimal value of $S_{\mathrm{c}}$ is estimated using a nonlinear least-squares method (Jones et al., 2001) which computes the sum of the square of the deviation between each measured $E^{*} R^{*}$ value and the value predicted by Eq. (5). This calculation is performed for a range of critical gradients until the $S_{\mathrm{c}}$ with the lowest corresponding deviation from the steady-state curve is found.

The accuracy of this optimized $S_{\mathrm{c}}$ value is constrained through bootstrapping the optimization procedure. The data are sampled with replacement to generate 100000 data sets, consisting of values randomly drawn from the population of patch or basin average data. For each of these sampled data sets the optimal value of $S_{\mathrm{c}}$ which minimizes the error between the data and the steady-state curve is calculated. The final $S_{\mathrm{c}}$ value for each landscape is the mean value of these 100000 iterations, with a $95 \%$ confidence interval.

Table 1 contains estimates of the critical gradient generated using both basin and patch average values alongside previously published values for Cascade Ridge, the Oregon Coast Range, and Gabilan Mesa. The predicted patch and basin average values for Gabilan Mesa and the Oregon Coast Range are similar to those published by Grieve et al. (2016b). This method of estimating the best-fit $S_{\mathrm{c}}$ will produce an average value representative of the maximum probability density of $S_{\mathrm{c}}$ values for a landscape, whereas the method of $S_{\mathrm{c}}$ estimation employed by Roering et al. (1999) can better be considered as the maximum $S_{\mathrm{c}}$ value for a landscape Grieve et al. (2016b).

The data for Cascade Ridge show better agreement with the value used by Hurst et al. (2012), which was also derived using $E^{*} R^{*}$ data, than the lower estimate from Grieve et al. (2016b). The pair of $S_{\mathrm{c}}$ values calculated for each landscape are very similar, suggesting that, in large enough data sets, the constraint of $S_{\mathrm{c}}$ is insensitive to the spatial scale of 
Table 1. Previously published $S_{\mathrm{c}}$ values alongside the values generated from the best fit to the steady-state curve for the patch and basin average data.

\begin{tabular}{lccccc}
\hline & Roering et al. (2007) & Hurst et al. (2012) & Grieve et al. (2016b) & Patch average $^{\mathrm{a}}$ & Basin average $^{\mathrm{b}}$ \\
\hline Oregon Coast Range & $1.2 \pm 0.2$ & - & 0.79 & $0.83 \pm 0.01$ & $0.83 \pm 0.01$ \\
Gabilan Mesa & $1.2 \pm 0.4$ & - & 0.8 & $0.8_{-0.05}^{+0.06}$ & $0.8_{-0.04}^{+0.05}$ \\
Cascade Ridge & - & 0.8 & 0.72 & $0.78 \pm 0.02$ & $0.82 \pm 0.02$ \\
\hline
\end{tabular}

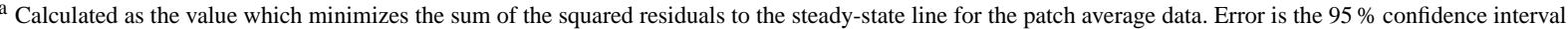
generated by bootstrapping the calculation 100000 times.

${ }^{\mathrm{b}}$ As above but using basin average data.

data averaging. However, the scale of spatial averaging has been demonstrated to have an impact on the interpretation of $E^{*} R^{*}$ data and thus care must be taken to select appropriate methods of spatial averaging and data processing in order to ensure that results generated are not simply a function of user-defined parameters.

The similarity of the average $S_{\mathrm{c}}$ values obtained using the bootstrapping procedure across three diverse landscapes highlights the presence of a distribution of $E^{*} R^{*}$ values existing for each landscape, and the nature of an average $S_{\mathrm{c}}$ measurement. Such a distribution occurs due to local variations in topography, process, and material properties, and similarities can be drawn between the results presented in Table 1 and other similar studies (DiBiase et al., 2010; Hurst et al., 2012).

The values of $S_{\mathrm{c}}$ constrained using this bootstrapping procedure are similar to those derived from the relationship between hillslope length and relief demonstrated by Grieve et al. (2016b); however, there is no need to estimate material properties such as the soil and rock density and thus this method provides an independent constraint on $S_{\mathrm{c}}$. However, the computational expense of bootstrapping the $S_{\mathrm{c}}$ fitting calculations from the $E^{*} R^{*}$ data is very high, when contrasted with the estimation of $S_{\mathrm{c}}$ using $L_{\mathrm{H}^{-}} R$ relationships presented by Grieve et al. (2016b). Additionally, using this bootstrapping method in landscapes which do not plot on the steadystate curve in $E^{*} R^{*}$ space can yield an incorrect $S_{\mathrm{c}}$ value with a low error estimate. Consequently, we recommend estimating the critical gradient of a landscape using this method and the method outlined in Grieve et al. (2016b), when field data are available, in order to best constrain the critical gradient of a landscape. However, careful consideration of the differences between a maximum $S_{\mathrm{c}}$ and a best-fit-derived average $S_{\mathrm{c}}$ should be undertaken to ensure that a valid geomorphic interpretation of a landscape is employed.

\section{Conclusions}

We present a software package which automates the extraction and processing of high-resolution topographic data to generate nondimensional erosion rate and relief measurements. Topographic data can be averaged at a hilltop scale by generating unique hilltop patches or can be averaged over drainage basins automatically extracted from the channel network. Alongside the raw data, these spatially averaged data sets are shown to reproduce the findings of previous studies. In steady-state landscapes such as the Oregon Coast Range and Gabilan Mesa, $E^{*} R^{*}$ data plot in a cluster around a single point on the steady-state curve, supporting the conclusions drawn in previous studies (Roering et al., 2007), and in Cascade Ridge, a transient erosion signal similar to that identified by Hurst et al. (2012) is observed. This technique is also tested on a landscape in the southern Appalachian Mountains, with the results suggesting that topography is decaying, supporting models of Miocene topographic rejuvenation proposed by Gallen et al. (2013). These results, alongside the ability to reproduce previous work, emphasize the value of this software to the geomorphology community as, until now, there has been no clear framework within which to produce nondimensional erosion rate and relief measurements.

The average critical gradient used in Eq. (1) is also constrained for three of the studied landscapes, with the values falling within expected ranges. However, due to the noise inherent in this form of analysis and the challenges of evaluating the goodness of fit between such noisy data and a model, it is recommended that other methods to constrain $S_{\mathrm{c}}$ using the same raw data be utilized instead. Finally, the influence of free parameters on the final interpretation of the data are explored, providing the user clear guidance on how to select parameters which control the level of smoothing or binning performed on the topographic data. The most significant of which are the minimum patch and basin size thresholds which must be carefully selected to balance smoothing the data with preserving landscape-scale trends.

\section{Data availability}

The data used to generate all the plots are published as "A nondimensional relief framework: data" (Grieve et al., 2016a). 


\section{Appendix A: Topographic metadata}

This table provides the accuracy information for the four point clouds used to generate the $1 \mathrm{~m}$ resolution topographic data used in this study. This information is compiled from metadata available from http://OpenTopography.org.

Table A1. Lidar point cloud metadata.

\begin{tabular}{lccc}
\hline Location & Point density $\left(\right.$ points per $\left.\mathrm{m}^{2}\right)$ & Vertical accuracy $(\mathrm{m})$ & Horizontal accuracy $(\mathrm{m})$ \\
\hline Oregon Coast Range & 6.55 & $0.07 \pm 0.03$ & 0.06 \\
Gabilan Mesa & 5.56 & $0.20 \pm 0.15$ & 0.11 \\
Cascade Ridge & 9.84 & $0.17 \pm 0.13$ & 0.11 \\
Coweeta & 8.91 & $0.17 \pm 0.13$ & 0.11 \\
\hline
\end{tabular}


Author contributions. S. W. D. Grieve developed the data analysis and visualization code and performed the data analysis. S. W. D. Grieve, S. M. Mudd, M. D. Hurst, and D. T. Milodowski wrote the topographic analysis code. S. W. D. Grieve wrote the manuscript with contributions from S. M. Mudd, M. D. Hurst, and D. T. Milodowski.

Acknowledgements. The topographic data used in this paper are freely available from http://www.opentopography.org. All the code used in this analysis is open source and can be downloaded from https://github.com/LSDtopotools/LSDTT_Hillslope_Analysis, http://github.com/sgrieve/ER_Star/, and http://github.com/sgrieve/ ER_Star_Figs/. The data used to generate all the plots are published as "A nondimensional relief framework: data" (Grieve et al., 2016a). S. W. D. Grieve is supported by NERC grant NE/J009970/1. S. M. Mudd is supported by US Army Research Office contract number W911NF-13-1-0478. D. T. Milodowski is supported by NERC grants NE/152830X/1 and J500021/1, in addition to the Harkness Award from the University of Cambridge. This paper is published with the permission of the Executive Director of the British Geological Survey and was supported in part by the Climate and Landscape Change research program at the British Geological Survey. We thank Fiona Clubb for discussions and advice which shaped the final form of the manuscript. The manuscript was improved through the detailed reviews provided by Jon Pelletier; an anonymous reviewer; and the associate editor, Susan Conway.

Edited by: S. Conway

\section{References}

Anders, A. M., Roe, G. H., Montgomery, D. R., and Hallet, B.: Influence of precipitation phase on the form of mountain ranges, Geology, 36, 479-482, doi:10.1130/G24821A.1, 2008.

Andrews, D. J. and Bucknam, R. C.: Fitting degradation of shoreline scarps by a nonlinear diffusion model, J. Geophys. Res.-Sol. Ea., 92, 12857-12867, doi:10.1029/JB092iB12p12857, 1987.

Baldwin, J. A., Whipple, K. X., and Tucker, G. E.: Implications of the shear stress river incision model for the timescale of postorogenic decay of topography, J. Geophys. Res.-Sol. Ea., 108, 2158, doi:10.1029/2001JB000550, 2003.

Benda, L. and Dunne, T.: Stochastic forcing of sediment supply to channel networks from landsliding and debris flow, Water Resour. Res., 33, 2849-2863, https://www.wou.edu/las/physci/ taylor/andrews_forest/refs/benda_dunne_1997.pdf, 1997.

Binnie, S. A., Phillips, W. M., Summerfield, M. A., and Fifield, L. K.: Tectonic uplift, threshold hillslopes, and denudation rates in a developing mountain range, Geology, 35, 743-746, doi:10.1130/G23641A.1, 2007.

Booth, A. M., Roering, J. J., and Rempel, A. W.: Topographic signatures and a general transport law for deep-seated landslides in a landscape evolution model, J. Geophys. Res.-Earth, 118, 603624, doi:10.1002/jgrf.20051, 2013.

Braun, J., Heimsath, A. M., and Chappell, J.: Sediment transport mechanisms on soil-mantled hillslopes, Geology, 29, 683-686,
doi:10.1130/0091-7613(2001)029<0683:STMOSM>2.0.CO;2, 2001.

Champagnac, J.-D., Molnar, P., Sue, C., and Herman, F.: Tectonics, climate, and mountain topography, J. Geophys. Res.-Sol. Ea., 117, B02403, doi:10.1029/2011JB008348, 2012.

Clarke, B. A. and Burbank, D. W.: Bedrock fracturing, threshold hillslopes, and limits to the magnitude of bedrock landslides, Earth Planet. Sc. Lett., 297, 577-586, doi:10.1016/j.epsl.2010.07.011, 2010.

Clarke, B. A. and Burbank, D. W.: Quantifying bedrock-fracture patterns within the shallow subsurface: Implications for rock mass strength, bedrock landslides, and erodibility, J. Geophys. Res.-Earth, 116, F04009, doi:10.1029/2011JF001987, 2011.

Clubb, F. J., Mudd, S. M., Milodowski, D. T., Hurst, M. D., and Slater, L. J.: Objective extraction of channel heads from highresolution topographic data, Water Resour. Res., 50, 4283-4304, doi:10.1002/2013WR015167, 2014.

Culling, W. E. H.: Analytical Theory of Erosion, The Journal of Geology, 68, 336-344, 1960.

DiBiase, R. A., Whipple, K. X., Heimsath, A. M., and Ouimet, W. B.: Landscape form and millennial erosion rates in the San Gabriel Mountains, CA, Earth Planet. Sc. Lett., 289, 134-144, doi:10.1016/j.epsl.2009.10.036, 2010.

DiBiase, R. A., Heimsath, A. M., and Whipple, K. X.: Hillslope response to tectonic forcing in threshold landscapes, Earth Surf Proc. Land., 37, 855-865, doi:10.1002/esp.3205, 2012.

Dietrich, W. E., Bellugi, D. G., Sklar, L. S., Stock, J. D., Heimsath, A. M., and Roering, J. J.: Geomorphic Transport Laws for Predicting Landscape form and Dynamics, in: Prediction in Geomorphology, edited by Wilcock, P. R. and Iverson, R. M., 103132, American Geophysical Union, Washington, DC, 2003.

Dillencourt, M. B., Samet, H., and Tamminen, M.: A General Approach to Connected-component Labeling for Arbitrary Image Representations, J. ACM, 39, 253-280, doi:10.1145/128749.128750, 1992.

Dohrenwend, J. C.: Systematic valley asymmetry in the central California Coast Ranges, Geol. Soc. Am. Bull., 89, 891900, doi:10.1130/0016-7606(1978)89<891:SVAITC>2.0.CO;2, 1978.

Dohrenwend, J. C.: Morphologic Analysis of Gabilan Mesa by Iterative Contour-Generalization: An Improved Method of Geomorphic Cartographic Analysis, SEPM Pacific Coast Paleogeography Field Guide \#4, Menlo Park, California, 83-87, available at: http://archives.datapages.com/data/pac_sepm/025/ 025001/pdfs/83.htm, 1979.

Foufoula-Georgiou, E., Ganti, V., and Dietrich, W. E.: A nonlocal theory of sediment transport on hillslopes, J. Geophys. Res.Earth, 115, F00A16, doi:10.1029/2009JF001280, 2010.

Furbish, D. J. and Fagherazzi, S.: Stability of creeping soil and implications for hillslope evolution, Water Resour. Res., 37, 2607 2618, doi:10.1029/2001WR000239, 2001.

Furbish, D. J. and Roering, J. J.: Sediment disentrainment and the concept of local versus nonlocal transport on hillslopes, J. Geophys. Res.-Earth, 118, 937-952, doi:10.1002/jgrf.20071, 2013.

Gabet, E. J., Pratt-Sitaula, B. A., and Burbank, D. W.: Climatic controls on hillslope angle and relief in the Himalayas, Geology, 32, 629-632, doi:10.1130/G20641.1, 2004.

Gabet, E. J., Mudd, S. M., Milodowski, D. T., Yoo, K., Hurst, M. D., and Dosseto, A.: Local topography and erosion rate control re- 
golith thickness along a ridgeline in the Sierra Nevada, California, Earth Surf. Proc. Land., 1779-1790, doi:10.1002/esp.3754, 2015.

Gallen, S. F., Wegmann, K. W., Frankel, K. L., Hughes, S., Lewis, R. Q., Lyons, N., Paris, P., Ross, K., Bauer, J. B., and Witt, A. C.: Hillslope response to knickpoint migration in the Southern Appalachians: implications for the evolution of postorogenic landscapes, Earth Surf. Proc. Land., 36, 1254-1267, doi:10.1002/esp.2150, 2011.

Gallen, S. F., Wegmann, K. W., and Bohnenstieh, D. R.: Miocene rejuvenation of topographic relief in the southern Appalachians, GSA Today, 23, 4-10, doi:10.1130/GSATG163A.1, 2013.

Grieve, S. W. D., Mudd, S. M., Hurst, M. D., and Milodowski, D. T.: A nondimensional relief framework: data, dataset, University of Edinburgh, School of GeoSciences, doi:10.7488/ds/1366, 2016a.

Grieve, S. W. D., Mudd, S. M., and Hurst, M. D.: How long is a hillslope?, Earth Surf. Proc. Land., doi:10.1002/esp.3884, 2016 b.

Hales, T. C., Ford, C. R., Hwang, T., Vose, J. M., and Band, L. E.: Topographic and ecologic controls on root reinforcement, J. Geophys. Res.-Earth, 114, F03013, doi:10.1029/2008JF001168, 2009.

Hales, T. C., Scharer, K. M., and Wooten, R. M.: Southern Appalachian hillslope erosion rates measured by soil and detrital radiocarbon in hollows, Geomorphology, 138, 121-129, doi:10.1016/j.geomorph.2011.08.030, 2012.

Hancock, G. R. and Evans, K. G.: Channel head location and characteristics using digital elevation models, Earth Surf. Proc. Land., 31, 809-824, doi:10.1002/esp.1285, 2006.

He, L., Chao, Y., and Suzuki, K.: A Run-Based Two-Scan Labeling Algorithm, IEEE T. Image Processing, 17, 749-756, doi:10.1109/TIP.2008.919369, 2008.

He, L.-F., Chao, Y.-Y., and Suzuki, K.: An Algorithm for Connected-Component Labeling, Hole Labeling and Euler Number Computing, J. Comput. Sci. Technol., 28, 468-478, doi:10.1007/s11390-013-1348-y, 2013.

Heimsath, A. M., Dietrich, W. E., Nishiizumi, K., and Finkel, R. C.: Stochastic processes of soil production and transport: erosion rates, topographic variation and cosmogenic nuclides in the Oregon Coast Range, Earth Surf. Proc. Land., 26, 531-552, doi:10.1002/esp.209, 2001.

Heimsath, A. M., Furbish, D. J., and Dietrich, W. E.: The illusion of diffusion: Field evidence for depth-dependent sediment transport, Geology, 33, 949-952, doi:10.1130/G21868.1, 2005.

Hilley, G. E. and Arrowsmith, J. R.: Geomorphic response to uplift along the Dragon's Back pressure ridge, Carrizo Plain, California, Geology, 36, 367-370, doi:10.1130/G24517A.1, 2008.

Hurst, M. D., Mudd, S. M., Walcott, R., Attal, M., and Yoo, K.: Using hilltop curvature to derive the spatial distribution of erosion rates, J. Geophys. Res.-Earth, 117, F02017, doi:10.1029/2011JF002057, 2012.

Hurst, M. D., Mudd, S. M., Attal, M., and Hilley, G.: Hillslopes Record the Growth and Decay of Landscapes, Science, 341, 868 871, doi:10.1126/science.1241791, 2013a.

Hurst, M. D., Mudd, S. M., Yoo, K., Attal, M., and Walcott, R.: Influence of lithology on hillslope morphology and response to tectonic forcing in the northern Sierra Nevada of California, J. Geophys. Res.-Earth, 118, 832-851, doi:10.1002/jgrf.20049, 2013b.

Jackson, M. and Roering, J. J.: Post-fire geomorphic response in steep, forested landscapes: Oregon Coast
Range, USA, Quaternary Sci. Rev., 28, 1131-1146, doi:10.1016/j.quascirev.2008.05.003, 2009.

Jones, E., Oliphant, T., and Peterson, P.: SciPy: Open source scientific tools for Python, available at: http://www.scipy.org/ (last access: 8 March 2015), 2001.

Kelsey, H. M., Ticknor, R. L., Bockheim, J. G., and Mitchell, E.: Quaternary upper plate deformation in coastal Oregon, Geol. Soc. Am. Bull., 108, 843-860, doi:10.1130/00167606(1996)108<0843:QUPDIC>2.3.CO;2, 1996.

Kim, H., Arrowsmith, J., Crosby, C. J., Jaeger-Frank, E., Nandigam, V., Memon, A., Conner, J., Baden, S. B., and Baru, C.: An efficient implementation of a local binning algorithm for digital elevation model generation of LiDAR/ALSM dataset, in: AGU Fall Meeting Abstracts, vol. 1, p. 0921, San Francisco, http://adsabs.harvard.edu/abs/2006AGUFM.G53C0921K, 2006.

Korup, O.: Rock type leaves topographic signature in landslidedominated mountain ranges, Geophys. Res. Lett., 35, L11402, doi:10.1029/2008GL034157, 2008.

Lashermes, B., Foufoula-Georgiou, E., and Dietrich, W. E.: Channel network extraction from high resolution topography using wavelets, Geophysical Research Letters, 34, L23S04, doi:10.1029/2007GL031140, 2007.

Lumia, R., Shapiro, L., and Zuniga, O.: A new connected components algorithm for virtual memory computers, Computer Vision, Graphics, and Image Processing, 22, 287-300, doi:10.1016/0734-189X(83)90071-3, 1983.

Matmon, A., Bierman, P. R., Larsen, J., Southworth, S., Pavich, M., and Caffee, M.: Temporally and spatially uniform rates of erosion in the southern Appalachian Great Smoky Mountains, Geology, 31, 155-158, doi:10.1130/00917613(2003)031<0155:TASURO>2.0.CO;2, 2003.

McKean, J. A., Dietrich, W. E., Finkel, R. C., Southon, J. R., and Caffee, M. W.: Quantification of soil production and downslope creep rates from cosmogenic $10 \mathrm{Be}$ accumulations on a hillslope profile, Geology, 21, 343-346, doi:10.1130/00917613(1993)021<343:QOSPAD>2.3.CO;2, 1993.

Milodowski, D. T., Mudd, S. M., and Mitchard, E. T.: Erosion rates as a potential bottom-up control of forest structural characteristics in the Sierra Nevada Mountains, Ecology, 96, 31-38, http://www.esajournals.org/doi/abs/10.1890/14-0649.1, 2015a.

Milodowski, D. T., Mudd, S. M., and Mitchard, E. T. A.: Topographic roughness as a signature of the emergence of bedrock in eroding landscapes, Earth Surf. Dynam., 3, 483-499, doi:10.5194/esurf-3-483-2015, 2015b.

Montgomery, D. R. and Foufoula-Georgiou, E.: Channel network source representation using digital elevation models, Water Resour. Res., 29, 3925-3934, doi:10.1029/93WR02463, 1993.

Montgomery, D. R., Sullivan, K., and Greenberg, H. M.: Regional test of a model for shallow landsliding, Hydrol. Process., 12, 943-955, 1998.

Mudd, S. M.: Detection of transience in eroding landscapes, Earth Surf. Proc. Land., doi:10.1002/esp.3923, 2016.

Mudd, S. M. and Furbish, D. J.: Influence of chemical denudation on hillslope morphology, J. Geophys. Res.-Earth, 109, F02001, doi:10.1029/2003JF000087, 2004.

Orlandini, S., Tarolli, P., Moretti, G., and Dalla Fontana, G.: On the prediction of channel heads in a complex alpine terrain using gridded elevation data, Water Resour. Res., 47, W02538, doi:10.1029/2010WR009648, 2011. 
Passalacqua, P., Do Trung, T., Foufoula-Georgiou, E., Sapiro, G., and Dietrich, W. E.: A geometric framework for channel network extraction from lidar: Nonlinear diffusion and geodesic paths, J. Geophys. Res.-Earth, 115, F01002, doi:10.1029/2009JF001254, 2010.

Pelletier, J. D.: A robust, two-parameter method for the extraction of drainage networks from high-resolution digital elevation models (DEMs): Evaluation using synthetic and real-world DEMs, Water Resour. Res., 49, 75-89, doi:10.1029/2012WR012452, 2013.

Perron, J. T., Kirchner, J. W., and Dietrich, W. E.: Formation of evenly spaced ridges and valleys, Nature, 460, 502-505, doi:10.1038/nature08174, 2009.

Reinhardt, L. and Ellis, M. A.: The emergence of topographic steady state in a perpetually dynamic self-organized critical landscape, Water Resour. Res., 51, 4986-5003, doi:10.1002/2014WR016223, 2015.

Reneau, S. L. and Dietrich, W. E.: Erosion rates in the southern oregon coast range: Evidence for an equilibrium between hillslope erosion and sediment yield, Earth Surf. Proc. Land., 16, 307-322, doi:10.1002/esp.3290160405, 1991.

Riebe, C. S., Kirchner, J. W., Granger, D. E., and Finkel, R. C.: Erosional equilibrium and disequilibrium in the Sierra Nevada, inferred from cosmogenic $26 \mathrm{Al}$ and $10 \mathrm{Be}$ in alluvial sediment, Geology, 28, 803-806, doi:10.1130/00917613(2000)28<803:EEADIT>2.0.CO;2, 2000.

Roering, J. J.: How well can hillslope evolution models "explain" topography? Simulating soil transport and production with highresolution topographic data, Geol. Soc. Am. Bull., 120, 12481262, doi:10.1130/B26283.1, 2008.

Roering, J. J., Kirchner, J. W., and Dietrich, W. E.: Evidence for nonlinear, diffusive sediment transport on hillslopes and implications for landscape morphology, Water Resour. Res., 35, 853870, doi:10.1029/1998WR900090, 1999.

Roering, J. J., Kirchner, J. W., and Dietrich, W. E.: Hillslope evolution by nonlinear, slope-dependent transport: Steady state morphology and equilibrium adjustment timescales, J. Geophys. Res.-Sol. Ea., 106, 16499-16513, doi:10.1029/2001JB000323, 2001

Roering, J. J., Perron, J. T., and Kirchner, J. W.: Functional relationships between denudation and hillslope form and relief, Earth Planet. Sc. Lett., 264, 245-258, doi:10.1016/j.eps1.2007.09.035, 2007.

Roering, J. J., Marshall, J., Booth, A. M., Mort, M., and Jin, Q.: Evidence for biotic controls on topography and soil production, Earth Planet. Sc. Lett., 298, 183-190, doi:10.1016/j.epsl.2010.07.040, 2010.

Rosenbloom, N. A. and Anderson, R. S.: Hillslope and channel evolution in a marine terraced landscape, Santa Cruz, California, J. Geophys. Res.-Sol. Ea., 99, 14013-14029, doi:10.1029/94JB00048, 1994.

Rosenfeld, A. and Pfaltz, J. L.: Sequential operations in digital picture processing, Journal of the ACM (JACM), 13, 471-494, 1966.

Samet, H.: Connected Component Labeling Using Quadtrees, J. ACM, 28, 487-501, doi:10.1145/322261.322267, 1981.

Schmidt, K. M., Roering, J. J., Stock, J. D., Dietrich, W. E., Montgomery, D. R., and Schaub, T.: The variability of root cohesion as an influence on shallow landslide susceptibility in the Ore- gon Coast Range, Canadian Geotechnical Journal, 38, 995-1024, doi:10.1139/t01-031, 2001.

Shreve, F.: The Vegetation of a Coastal Mountain Range, Ecology, 8, 27-44, doi:10.2307/1929384, 1927.

Small, E. E., Anderson, R. S., and Hancock, G. S.: Estimates of the rate of regolith production using $10 \mathrm{Be}$ and $26 \mathrm{Al}$ from an alpine hillslope, Geomorphology, 27, 131-150, doi:10.1016/S0169555X(98)00094-4, 1999.

Sofia, G., Pirotti, F., and Tarolli, P.: Variations in multiscale curvature distribution and signatures of LiDAR DTM errors, Earth Surf. Proc. Land., 38, 1116-1134, doi:10.1002/esp.3363, 2013.

Stock, G. M., Anderson, R. S., and Finkel, R. C.: Pace of landscape evolution in the Sierra Nevada, California, revealed by cosmogenic dating of cave sediments, Geology, 32, 193-196, doi:10.1130/G20197.1, 2004.

Stock, J. and Dietrich, W. E.: Valley incision by debris flows: Evidence of a topographic signature, Water Resour. Res., 39, 1089, doi:10.1029/2001WR001057, 2003.

Suzuki, K., Horiba, I., and Sugie, N.: Linear-time connectedcomponent labeling based on sequential local operations, Computer Vision and Image Understanding, 89, 1-23, doi:10.1016/S1077-3142(02)00030-9, 2003.

Sweeney, K. E., Roering, J. J., and Ellis, C.: Experimental evidence for hillslope control of landscape scale, Science, 349, 51-53, doi:10.1126/science.aab0017, 2015.

Swift Jr., L. W., Cunningham, G. B., and Douglass, J. E.: Climatology and Hydrology, in: Forest Hydrology and Ecology at Coweeta, edited by Swank, W. T. and Jr, D. A. C., no. 66 in Ecological Studies, 35-55, Springer New York, http://link.springer. com/chapter/10.1007/978-1-4612-3732-7_3, 1988.

Tarolli, P.: High-resolution topography for understanding Earth surface processes: Opportunities and challenges, Geomorphology, 216, 295-312, doi:10.1016/j.geomorph.2014.03.008, 2014.

Tarolli, P. and Dalla Fontana, G.: Hillslope-to-valley transition morphology: New opportunities from high resolution DTMs, Geomorphology, 113, 47-56, doi:10.1016/j.geomorph.2009.02.006, 2009.

Tseng, C.-M., Lin, C.-W., Dalla Fontana, G., and Tarolli, P.: The topographic signature of a major typhoon, Earth Surf. Proc. Land., 40, 1129-1136, doi:10.1002/esp.3708, 2015.

Tucker, G. E. and Bradley, D. N.: Trouble with diffusion: Reassessing hillslope erosion laws with a particle-based model, J. Geophys. Res.-Earth, 115, F00A10, doi:10.1029/2009JF001264, 2010.

Tucker, G. E. and Slingerland, R.: Drainage basin responses to climate change, Water Resour. Res., 33, 2031-2047, doi:10.1029/97WR00409, 1997.

Tucker, G. E., Catani, F., Rinaldo, A., and Bras, R. L.: Statistical analysis of drainage density from digital terrain data, Geomorphology, 36, 187-202, doi:10.1016/S0169-555X(00)000568, 2001.

Wiener, N.: Extrapolation, interpolation, and smoothing of stationary time series, vol. 2, MIT press Cambridge, MA, available at: http://tocs.ulb.tu-darmstadt.de/129776289.pdf, 1949.

Wobus, C., Whipple, K. X., Kirby, E., Snyder, N., Johnson, J., Spyropolou, K., Crosby, B., and Sheehan, D.: Tectonics from topography: Procedures, promise, and pitfalls, Geological Society of America Special Papers, 398, 55-74, doi:10.1130/2006.2398(04), 2006. 